\title{
Liveweight prediction from hip height, condition score, fetal age and breed in tropical female cattle
}

\author{
Geoffry Fordyce ${ }^{\mathrm{A}, \mathrm{B}, \mathrm{G}}$, Angela Anderson ${ }^{\mathrm{C}}$, Kieren McCosker ${ }^{\mathrm{D}}$, Paul J. Williams ${ }^{\mathrm{A}, \mathrm{E}}$, \\ Richard G. Holroyd $^{\mathrm{A}, \mathrm{F}}$, Nick J. Corbet ${ }^{\mathrm{A}, \mathrm{E}}$ and Michael S. Sullivan ${ }^{\mathrm{A}, \mathrm{F}}$ \\ ${ }^{A}$ Cooperative Research Centre for Beef Genetic Technologies, University of New England, Armidale, \\ NSW 2351, Australia. \\ ${ }^{B}$ Centre for Animal Science, Queensland Alliance for Agriculture and Food Innovation, The University \\ of Queensland, Qld 4067, Australia. \\ ${ }^{\mathrm{C}}$ Agri-Science Queensland, Department of Agriculture, Fisheries and Forestry, Spyglass Beef Cattle \\ Research Facility, MS 99, Charters Towers, Qld 4820, Australia. \\ DDepartment of Resources, Katherine Research Station, NT 0851, Australia. \\ ${ }^{E}$ CSIRO Livestock Industries, PO Box 5545, Rockhampton, Qld 4702, Australia. \\ ${ }^{\mathrm{F}}$ Agri-Science Queensland, Department of Agriculture, Fisheries and Forestry, PO Box 6014, \\ Rockhampton, Qld 4702, Australia. \\ ${ }^{\mathrm{G}}$ Corresponding author. Email: g.fordyce@uq.edu.au
}

\begin{abstract}
Hip height, body condition, subcutaneous fat, eye muscle area, percentage Bos taurus, fetal age and diet digestibility data were collected at 17372 assessments on 2181 Brahman and tropical composite (average $28 \%$ Brahman) female cattle aged between 0.5 and 7.5 years of age at five sites across Queensland. The study validated the subtraction of previously published estimates of gravid uterine weight to correct liveweight to the non-pregnant status. Hip height and liveweight were linearly related (Brahman: $P<0.001, R^{2}=58 \%$; tropical composite $P<0.001, R^{2}=67 \%$ ). Liveweight varied by $12-14 \%$ per body condition score $(5$-point scale) as cows differed from moderate condition $(P<0.01)$. Parallel effects were also found due to subcutaneous rump fat depth and eye muscle area, which were highly correlated with each other and body condition score $(r=0.7-0.8)$. Liveweight differed from average by $1.65-1.66 \%$ per mm of rump fat depth and $0.71-0.76 \%$ per $\mathrm{cm}^{2}$ of eye muscle area $(P<0.01)$. Estimated dry matter digestibility of pasture consumed had no consistent effect in predicting liveweight and was therefore excluded from final models. A method developed to estimate full liveweight of post-weaning age female beef cattle from the other measures taken predicted liveweight to within 10 and $23 \%$ of that recorded for 65 and $95 \%$ of cases, respectively. For a $95 \%$ chance of predicted group average liveweight (body condition score used) being within 5, 4, 3, 2 and $1 \%$ of actual group average liveweight required 23, 36, 62, 137 and 521 females, respectively, if precision and accuracy of measurements matches that used in the research. Non-pregnant Bos taurus female cattle were calculated to be $10-40 \%$ heavier than Brahmans at the same hip height and body condition, indicating a substantial conformational difference. The liveweight prediction method was applied to a validation population of 83 unrelated groups of cattle weighed in extensive commercial situations on 119 days over 18 months (20 917 assessments). Liveweight prediction in the validation population exceeded average recorded liveweight for weigh groups by an average of $19 \mathrm{~kg}(\sim 6 \%)$ demonstrating the difficulty of achieving accurate and precise animal measurements under extensive commercial grazing conditions.
\end{abstract}

Additional keywords: beef cattle, pregnancy, tropics.

Received 24 July 2012, accepted 9 October 2012, published online 14 January 2013

\section{Background}

Liveweight is a primary indicator of beef cattle values as it is a predictor of carcass weight. The accuracy of weighing in commercial situations for research or commercial purposes can be substantially affected by handling protocols (e.g. Robbins et al. 1982; Fordyce et al. 2008), which indicates that though liveweight may be measured precisely, it may not necessarily be an accurate indicator of carcass or empty bodyweight. No practical method for predicting liveweight as a means to assess the accuracy of liveweights taken is currently available. Such a method may also be useful to commercial or research situations where scales are either unavailable or dysfunctional and where liveweights are a critical measure. Further, a clear understanding of how liveweight is related to traits such as height, body condition and genotype is of value in cattle management. 
In research of breeding cattle liveweights, the estimated weight of a pregnancy (Silvey and Haydock 1978; O'Rourke et al. 1991) is regularly subtracted to derive equivalent nonpregnant liveweight, despite there being no reported validation of this method.

This paper examines the hypothesis that average liveweight of cattle groups can be accurately predicted from estimates of individual liveweights using simple linear and subjective measures.

\section{Method}

\section{Ethics approval}

Conduct of the test group study reported here was approved for 1999-2006 and 2006-10 by the JM Rendel Laboratory Animal Experimental Ethics Committee (CSIRO, Queensland) as approvals TBC107 and RH225-06, respectively. The validation population study was approved by The University of Queensland Ethics Committee as approvals SVS/729/07/MLA and SVS/756/08/MLA.

\section{Environment}

Relevant climatic and environmental conditions at four of the five Queensland research stations (Swan's Lagoon in the north-east; Toorak in the north-west; Belmont in central east; Brian Pastures in the south-east) used in this study have been described by Barwick et al. (2009). The fifth research station (Brigalow in central Queensland) has been described by Burns et al. (1997). All five sites experience three main seasonal periods: a wet season, which is a hot moist period where most annual pasture growth occurs between the start of the storm season (usually between September and January and on average in December) and April, the early dry season, which is a cool dry period between May and August, and late dry season, which is a hot dry period between September and the start of the storm season. In going to the north and west of Queensland, except on the coast, the climate becomes increasingly hotter and drier with a later start to the wet season on average. Cattle growth is usually high in the wet season, reducing to maintenance in the early dry season, and progressing to weight loss in the late dry season.

\section{Animals}

Test group. Female Brahman (B100) and tropical composite (B028) cattle $(n=2181)$ in 4 year groups were allocated and transported as required from eight Queensland and Northern Territory sites as newly weaned calves to four sites (excludes Brigalow) across Queensland (Table 1). The B028 cattle averaged 28\% Brahman (Bos indicus), 21\% British breed, 5\% European breed and $46 \%$ tropically adapted African Bos taurus. These animals were managed within age groups to 2.5 years of age, from which time they were managed within one or two genotype groups within site. Annual multiple-sire mating was for 12 weeks and first calving for each group was at 3 years of age. Animals were retained unless they failed to wean a calf in 2 consecutive years, or developed physical or behavioural problems. One Toorak management group was transferred to a fifth site (Brigalow) for 18 months due to drought conditions; it was replaced by another management group from Brian Pastures (Table 1).
Table 1. Age, genotype, numbers, and location of cattle in the test group

\begin{tabular}{|c|c|c|c|c|}
\hline$\overline{\text { Site }}$ & Birth year & Genotype $^{\mathrm{A}}$ & $n$ & Comment \\
\hline \multirow[t]{7}{*}{ Belmont } & 1999-00 & B100 & 73 & - \\
\hline & $2000-01$ & B100 & 111 & - \\
\hline & $2000-01$ & B028 & 113 & - \\
\hline & 2001-02 & B100 & 119 & - \\
\hline & 2001-02 & B028 & 140 & - \\
\hline & $2002-03$ & B100 & 124 & - \\
\hline & $2002-03$ & B028 & 48 & - \\
\hline \multirow[t]{3}{*}{ Brian Pastures } & $2000-01$ & B028 & 146 & $\begin{array}{l}65 \% \text { shifted } \\
\text { to Brigalow, } \\
\text { April } 2007\end{array}$ \\
\hline & $2001-02$ & B028 & 272 & $\begin{array}{l}58 \% \text { shifted } \\
\text { to Brigalow, } \\
\text { April } 2007\end{array}$ \\
\hline & $2002-03$ & B028 & 79 & - \\
\hline \multirow[t]{3}{*}{ Swan's Lagoon } & $2000-01$ & $\mathrm{~B} 100$ & 188 & - \\
\hline & $2001-02$ & B100 & 219 & - \\
\hline & $2002-03$ & B100 & 42 & - \\
\hline \multirow[t]{4}{*}{ Toorak } & $2000-01$ & B100 & 65 & - \\
\hline & $2000-01$ & B028 & 160 & $\begin{array}{l}43 \% \text { at Brigalow: } \\
\text { Sept. 2005- } \\
\text { March } 2007\end{array}$ \\
\hline & $2001-02$ & B100 & 98 & \\
\hline & $2001-02$ & B028 & 184 & $\begin{array}{l}50 \% \text { to Brigalow: } \\
\text { Sept. 2005- } \\
\text { March } 2007\end{array}$ \\
\hline
\end{tabular}

${ }^{\mathrm{A}} \mathrm{B} 028$ and B100 denote 28 and $100 \%$ Brahman, respectively.

Validation population. Cows from 83 groups were assessed on a total 119 days (Table 2; 20917 assessments: March 2008 to September 2009; McGowan 2012) and the data was used to validate the liveweight prediction method. These cows were unrelated to the test group and were sourced from across Queensland and the Northern Territory. Average genotype for each group was visually estimated and ranged from 0 to $100 \%$ Bos indicus.

\section{Measurements}

Test group. After relocation at weaning to each site, the cattle were mustered thereafter each 4-8 weeks for assessments of reproductive and growth parameters. Measures included liveweight, body condition score (CS5; 5-point scale in thirdscore increments: poor, backward, moderate, forward and fat; Gaden 2005), subcutaneous fat depth at the P8 site (position 8 within many other positions in previous research to identify the optimum fat depth measurement site), which is on the rump adjacent to the sacral crest (Johnson and Vidyadaran 1981), eye muscle area at the level of the 12/13 rib (EMA), hip height (at the peak of the sacrum), and fetal age if pregnant. Electronic scales registered an error range of $2 \mathrm{~kg}$. Weighing protocol was confounded with site (Table 3). P8 fat depth, EMA and fetal age were determined using linear array real-time ultrasound with probes ranging from 3.5 to $10 \mathrm{MHz}$. At regular intervals at each site, faecal samples were collected and analysed using nearinfrared spectrophotometry to estimate diet dry matter digestibility (DMD; Coates and Dixon 2008). 
Table 2. Cattle in the validation population

\begin{tabular}{|c|c|c|c|c|c|c|c|c|c|}
\hline \multirow[t]{2}{*}{ \% Brahman } & \multicolumn{3}{|c|}{$\begin{array}{c}\text { Central and southern } \\
\text { Queensland }\end{array}$} & \multicolumn{3}{|c|}{$\begin{array}{c}\text { Northern } \\
\text { Queensland }\end{array}$} & \multicolumn{3}{|c|}{$\begin{array}{c}\text { Northern Territory and northern } \\
\text { Western Australia }\end{array}$} \\
\hline & Groups & $n$ & Avg. weight ${ }^{\mathrm{A}}$ & Groups & $n$ & Avg. weight & Groups & $n$ & Avg. weight \\
\hline 0 & 5 & 888 & 429 & 1 & 17 & 309 & - & - & - \\
\hline $25-50$ & 9 & 1027 & 455 & - & - & - & 1 & 615 & 490 \\
\hline 50 & 11 & 2313 & 440 & 3 & 1201 & 438 & - & - & - \\
\hline $50-75$ & 10 & 2580 & 443 & 1 & 202 & 358 & 2 & 506 & 443 \\
\hline $75-100$ & 18 & 3232 & 469 & 5 & 2297 & 408 & 2 & 235 & 375 \\
\hline 100 & 2 & 232 & 517 & 7 & 2023 & 388 & 6 & 3549 & 371 \\
\hline
\end{tabular}

${ }^{\mathrm{A}}$ Average recorded liveweight $(\mathrm{kg})$.

Data was collated for all cases in the database between March 2002 and May 2007, inclusive, where all the following information was available for individuals on the day of weighing: liveweight, hip height, condition score, fat depth, fetal age and estimated dietary DMD; $n=17372$. EMA was available for $91 \%$ of these cases.

Validation population. All cows were weighed, hip height measured, body condition scored (1-5) and fetal age estimated to the nearest month by rectal palpation. Estimated average time since access to feed and water was recorded. Data were recorded by experienced cattle veterinarians $(n=35)$, whose training (and calibration) in taking each of the specific measures required ranged from limited to very detailed.

\section{Analyses}

Test group. The methods used to analyse the data were designed to generate prediction equations for liveweight of female cattle in north Australia. Except for fetal age, all of the effects on liveweight of the other measures are much more likely to have proportional and not absolute effects on liveweight. For example, a difference in condition score is more likely to be related to a percentage difference in liveweight than to an absolute liveweight difference if considered across a large range in other parameters such as age. Therefore, the method was to predict liveweight from hip height with other effects on liveweight, except for fetal age effects, adjusted proportionately.

Initially, a subset of data (10807 cases) was selected and included all cases where measurements taken on a date within site included a minimum of five non-pregnant and five pregnant animals. This data was used to test application of the prediction equations of O'Rourke et al. (1991) and Silvey and

Table 3. Weighing protocols used in the test group

\begin{tabular}{ll}
\hline Site & Protocol \\
\hline $\begin{array}{c}\text { Belmont and } \\
\text { Brigalow } \\
\text { Brian Pastures }\end{array}$ & $\begin{array}{c}\text { Transferred to a small paddock the previous day, then } \\
\text { mustered at sunrise and weighed immediately } \\
\text { Mustered during the day from the paddock they grazed and } \\
\text { weighed immediately } \\
\text { Tustered on day before weighing; held in yards overnight } \\
\text { on water without feed for an average of 14 h before } \\
\text { weighing } \\
\text { Swan's Lagoon } \\
\text { Mustered on day before weighing; held in yards overnight } \\
\text { for an average of 16h from 5 pm without access to either } \\
\text { water or feed before weighing }\end{array}$ \\
\hline
\end{tabular}

Haydock (1978) to correct liveweight for stage of pregnancy. Data for animals less than 2.5 years of age were also excluded when testing this liveweight correction equation. Linear regression (Payne et al. 2008) was used to analyse uncorrected liveweight with a model of: Constant + Hip height + Error. The percentage error in liveweight prediction, i.e. (actual liveweight predicted liveweight)/actual liveweight $\times 100$, was then modelled using multiple linear regression (Payne et al. 2008). The model used was: Constant + Genotype + Site + Genotype.Site + CS5 + DMD + Days pregnant + Error. Age was not included in the model as it is correlated with both hip height and liveweight. The error predictions for days pregnant (in 10-day intervals) were calculated. Linear regression was used to define the relationship between these error predictions and days pregnant.

Once the process of liveweight correction for stage of pregnancy was validated, the full dataset was analysed using liveweight initially corrected for days pregnant. Data from B100 and B028 cattle were analysed separately to reduce the impact of imbalanced allocation of genotypes across sites. In further analyses, CS5 was replaced by either EMA or P8 fat depth.

In all analyses, only main effects and two-way interactions were tested. Statistically significant interactions were retained only if their inclusion increased the error variation explained and they demonstrated effects of potential biological significance. Independent variables were all included as factors (Table 4) initially. In final models, CS5, P8 fat depth or EMA were

Table 4. Levels for variables when included as factors in analyses

\begin{tabular}{lc}
\hline Genotype $^{\mathrm{A}}$ & 2-level factor: B100 and B028 \\
\hline Site & 4-level factor for tropical composites: Belmont, \\
& Toorak, Brian Pastures, Brigalow \\
& 3-level factor for Brahmans: Belmont, Toorak, Swan's \\
& Lagoon \\
Condition score & 1-5 scale in increments of one-third of a score; range of \\
& $0.67-5.00$ \\
P8 fat depth & 9-level factor; each level is 3 mm; highest level is $>24$ \\
& mm \\
Eye muscle area & 7-level factor; each level is $10 \mathrm{~cm}^{2}$; highest level is $>80$ \\
& $\mathrm{~cm} 2$ \\
Stage of pregnancy & 11-level factor; non-pregnant, and then each level is \\
& 30 days; highest is $>270$ days \\
Dry matter & 8-level factor: each level is $2 \%$; $4-48 \%$ up to $61-62 \%$ \\
digestibility & \\
\hline
\end{tabular}

${ }^{\mathrm{A}} \mathrm{B} 028$ and B100 denote 28 and $100 \%$ Brahman, respectively. 
fitted as continuous variables rather than as factors with the selected fit (e.g. linear) to match noted patterns in effects. Adjusted $R^{2}$ values are presented; these were calculated as: [1Residual mean square/Total mean square) $\times 100 \%$ ]

Validation population. Data was only submitted for analysis if the number of animals within the site $\times$ date $\times$ genotype $\times$ weighing protocol group was at least 10 . The liveweight prediction method was applied after the following curfew effects on liveweight (Fordyce et al. 2008) were corrected: $-8 \%$ for cows without access to feed and water for 1 day; -2 , -4 and $-6 \%$ if access to water but not feed for 1,2 and 3 days, respectively; $-5 \%$ if yarded for 1 day and access to feed and water was variable; nil if measured on the same day as mustering.

\section{Results}

Plots against age demonstrated large season effects on liveweight, body condition, P8 fat depth and EMA change but not hip height change (Fig. 1). The correlations of condition score with P8 fat depth and EMA were 0.79 and 0.69 , respectively, and between
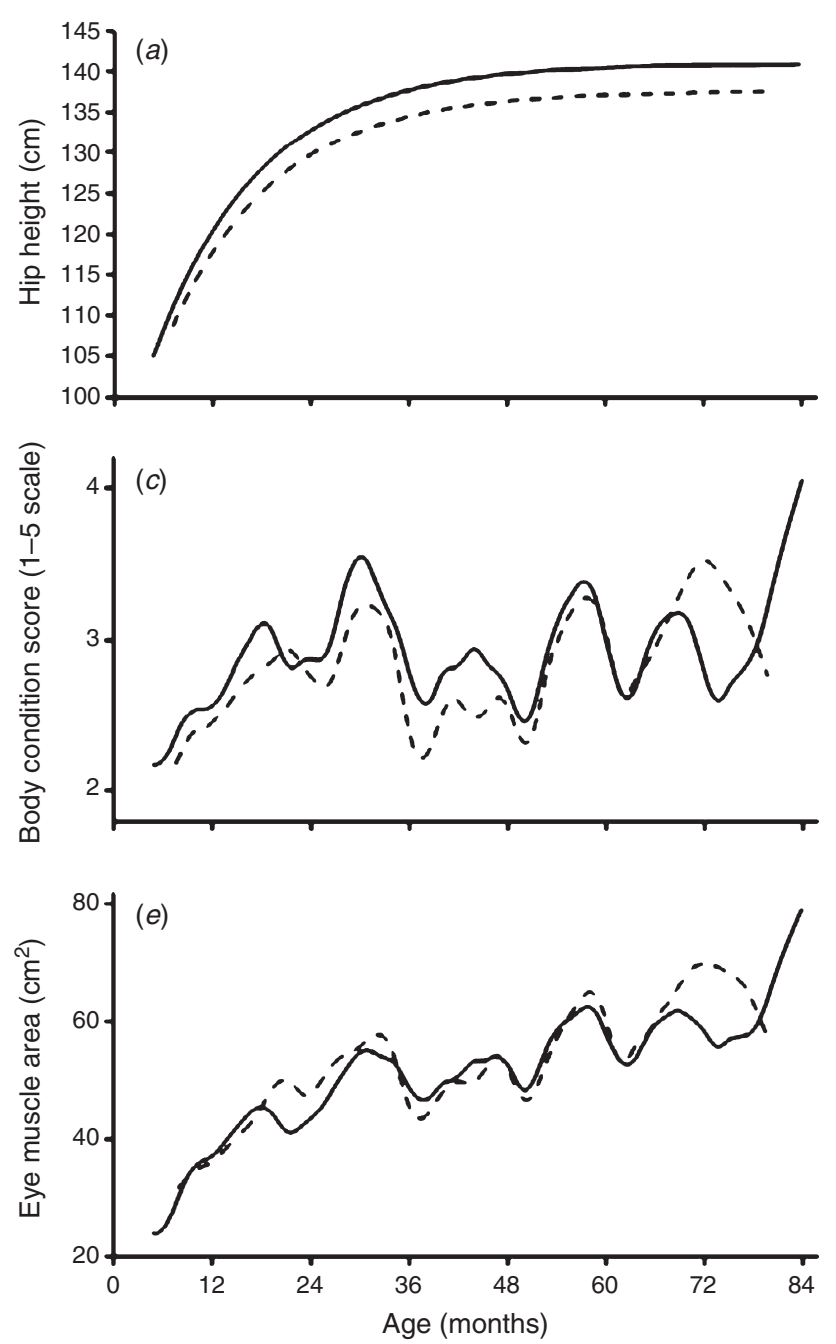

P8 fat depth and EMA was 0.69. In these plots, B100 cattle had similar body condition, but were taller and lighter than B028 cattle.

When a range of best-fit curves was fitted to the relationship between liveweight corrected for fetal age and hip height, the percentage variation that could be accounted for was maximised at $58 \%$ using an exponential relationship, but $57 \%$ with a linear relationship (Fig. 2). As there was little difference between the fit of the exponential and linear models, the errors from the linear regression were used as the independent variate in the multiple regression analyses. Prediction equations for pregnancycorrected liveweight from hip height for the two genotype groups were: $10.91 *$ Hip height $(\mathrm{cm})-1017$ in B028 cattle $\left(P<0.001, R^{2}=67 \%\right) ; 10.29 *$ Hip height $(\mathrm{cm})-989$ in $\mathrm{B} 100$ cattle $\left(P<0.001, R^{2}=58 \%\right)$.

For the subset of data with comparable pregnant and nonpregnant animals aged more than 2.5 years, the linear model for percentage error in liveweight prediction regressed against stage of pregnancy (expressed in 10-day intervals) was: $-6.1+0.03942$
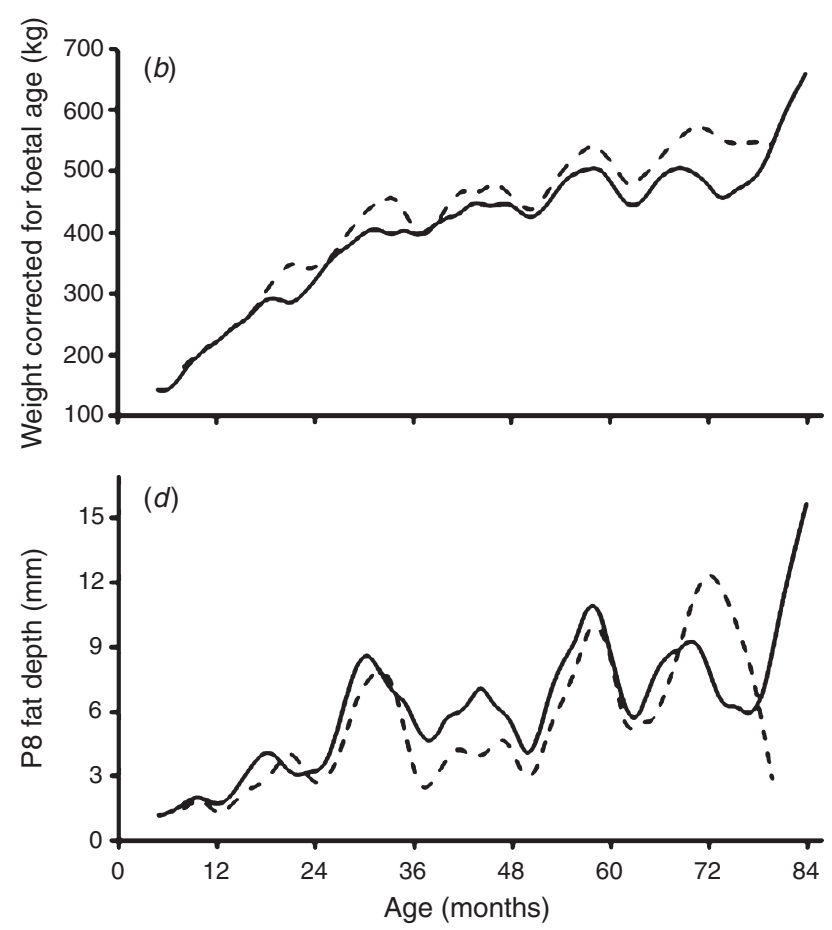

Fig. 1. Growth curves using averages against age (nearest month) for Brahman ( $\longrightarrow$ ) and tropical composite (- = = =) female cattle aged 0.5-7.5 years in the test group: $(a)$ exponential fitted line for hip height; spline fits (30 degrees of freedom) for $(b)$ liveweight adjusted for fetal age and site, (c) body condition score, $(d)$ P8 fat depth, and $(e)$ eye muscle area. 


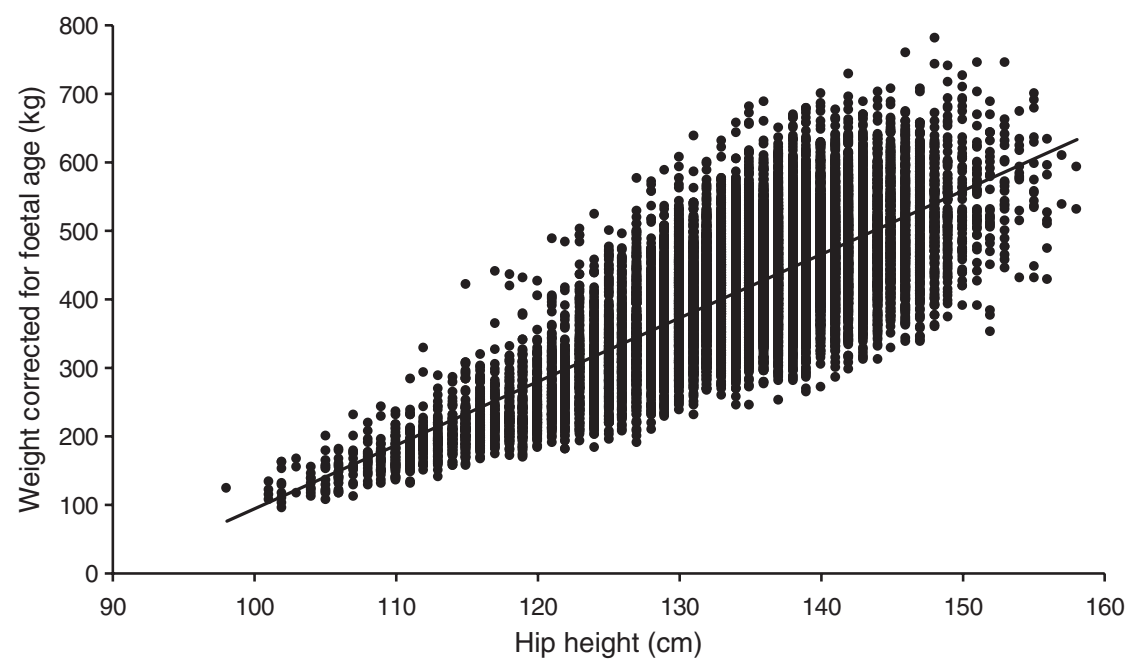

Fig. 2. The linear relationship between hip height and liveweight corrected for fetal age in Brahman and tropical composite female cattle aged $0.5-7.5$ years in the test group. Liveweight $(\mathrm{kg})=9.592 * \mathrm{Hip}$ height $(\mathrm{cm})-864\left(P<0.001 ; R^{2}=57 \%\right)$.

* Days pregnant; $P<0.001, R^{2}=56 \%$, s.e. $=2.63$. The effect of days pregnant on cow liveweight did not differ significantly from the calculated weights of the gravid uterus (Fig. 3).

In the multiple regressions of percentage error in liveweight prediction, all the dependent factors (Site, CS5/P8 fat depth/ EMA, DMD) had a significant effect $(P<0.001)$. However, DMD had a completely random effect on the liveweight-hip height relationship and was therefore excluded from further analyses. Several interactions were significant. Together, their inclusion explained $<1 \%$ of liveweight variance, and because each appeared to be a random effect, they were excluded from final models. CS5, P8 fat depth, and EMA each had a linear effect on the proportional error in predicting liveweight from hip height $(P<0.001)$ and were therefore fitted as covariates in final models (Table 5).

Results from these analyses were used to derive equations that estimated liveweight of post-weaning age female beef cattle (Table 6).

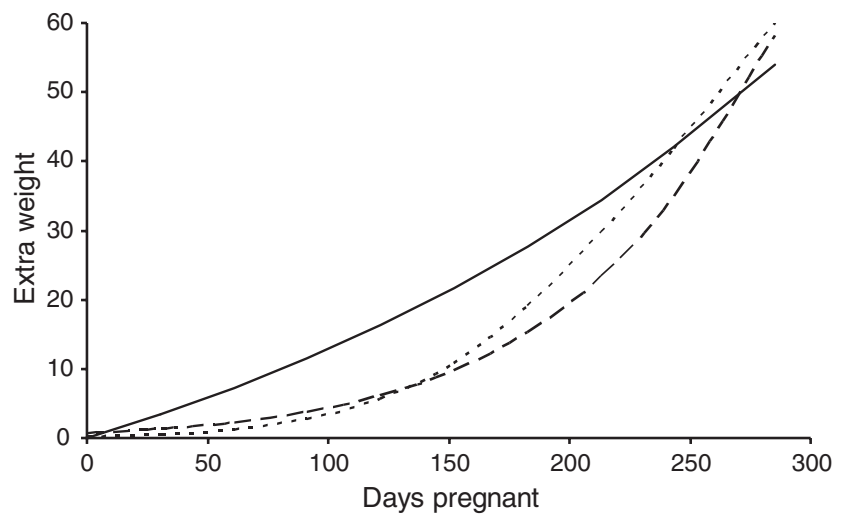

Fig. 3. The extra liveweight due to pregnancy in a typical 500-kg mature cow (solid line; s.e. $=13.2 \mathrm{~kg}$ ) compared with predicted effects from the weight of the products of conception when estimated calf birthweight is $33.5 \mathrm{~kg}$ (O'Rourke et al. 1991, dashes; Silvey and Haydock 1978, dotted line).

Table 5. Values for prediction equations of percentage error in pregnancy-corrected liveweight calculation from hip height

\begin{tabular}{lcccccc}
\hline $\begin{array}{l}\text { Genotype } \\
\text { Covariate: }\end{array}$ & $\begin{array}{c}\text { B028 } \\
\text { CS5 } \\
(1-5)\end{array}$ & $\begin{array}{c}\text { B028 } \\
\text { P8 fat depth } \\
(\mathrm{mm})\end{array}$ & $\begin{array}{c}\text { B028 } \\
\text { EMA } \\
\left(\mathrm{cm}^{2}\right)\end{array}$ & $\begin{array}{c}\text { B100 } \\
\text { CS5 } \\
(1-5)\end{array}$ & $\begin{array}{c}\text { B100 } \\
\text { P8 fat depth } \\
(\mathrm{mm})\end{array}$ & $\begin{array}{c}\text { B100 } \\
\text { EMA } \\
\left(\mathrm{cm}^{2}\right)\end{array}$ \\
\hline$R^{2}$ & $38.4 \%$ & $34.3 \%$ & $38.8 \%$ & $39.4 \%$ & $40.0 \%$ & $44.5 \%$ \\
Covariate mean & 2.73 & 4.97 & 51.6 & 2.93 & 6.55 & 52.9 \\
s.e. & 12.0 & 12.4 & 12.0 & 12.3 & 12.2 & 11.6 \\
Intercept & -36.8 & -6.33 & -36.3 & -33.0 & -8.01 & -38.5 \\
Regression coefficient & 13.53 & 1.66 & 0.717 & 12.23 & 1.65 & 0.757 \\
Site effects (\% error) & & & & & - & - \\
$\quad$ Brian Pastures & -3.20 & -4.23 & -2.20 & - & - & - \\
$\quad$ Brigalow & 6.80 & 2.47 & 2.58 & - & -8.89 & -6.64 \\
$\quad$ Swan's Lagoon & - & - & - & -10.23 & -3.52 & -2.38 \\
$\quad$ Toorak & -6.54 & -8.80 & -6.68 & -2.07 & -3.52 & \\
\hline
\end{tabular}

${ }^{\mathrm{A}} \mathrm{B} 028$ and $\mathrm{B} 100$ denote 28 and $100 \%$ Brahman, respectively.

${ }^{\mathrm{B}}$ Full liveweight at Belmont is the reference value. 
Table 6. Method of predicting liveweight of post-weaning age female beef cattle

\begin{tabular}{|c|c|c|}
\hline $\begin{array}{l}\text { Calculate expected full paddock } \\
\text { liveweight }(\mathrm{kg}) \text { from height of cattle }\end{array}$ & $\begin{array}{l}\text { B028 weight } \\
\text { B100 weight }\end{array}$ & $\begin{array}{l}\mathrm{a}=10.91 * \text { Hip height }(\mathrm{cm})-1017 \\
\mathrm{~b}=10.29 * \text { Hip height }(\mathrm{cm})-989\end{array}$ \\
\hline Correct for CS $(1-5 \text { scale })^{\mathrm{A}}$ & $\begin{array}{l}\text { B028 weight } \\
\text { B100 weight }\end{array}$ & $\begin{array}{l}=\mathrm{a} *[1+(13.53 *(\mathrm{CS} 5-2.73)) / 100] \\
=\mathrm{b} *[1+(12.23 *(\mathrm{CS} 5-2.73)) / 100]\end{array}$ \\
\hline $\begin{array}{l}\text { Percentage } \text { Bos taurus adjustment }{ }^{\mathrm{B}} \\
\text { Curfew adjustment }\end{array}$ & & $\begin{array}{l}\mathrm{c}=\mathrm{B} 100 \text { weight }+(\mathrm{B} 028 \text { weight }-\mathrm{B} 100 \text { weight }) * \text { Bos taurus }(\%) / 0.72 \\
\mathrm{~d}=\mathrm{c} /(1-\text { Expected percentage reduction in liveweight due to curfew })\end{array}$ \\
\hline $\begin{array}{l}\text { Add the expected weight of pregnancy } \\
\text { (O'Rourke } \text { et al. 1991) }\end{array}$ & Liveweight & $=\mathrm{d}+2.718^{\wedge}\left[-0.309+0.133 *\right.$ Days pregnant $\left./ 7-0.00063 *(\text { Days pregnant } / 7)^{\wedge} 2\right]$ \\
\hline
\end{tabular}

${ }^{\mathrm{A}}$ Alternatively, can correct for fatness using either P8 fat depth or EMA.

${ }^{\mathrm{B}}$ Assumes a linear effect of percentage Bos taurus on predicted liveweight.

When the liveweight prediction method was tested using data from 83 unrelated groups, the group average liveweight was overestimated by an average of $19 \mathrm{~kg}$ (Fig. 4). Prediction error for individuals in the validation population was higher than within the test group, with 9 percentage units more predictions with an error of $>20 \%$ (Fig. 5).

\section{Discussion}

This study has described a method to estimate full liveweight of post-weaning age female beef cattle using basic parameters. The models developed explained $\sim 60 \%$ of variation. The relatively low precision of the method means its application is only for estimating average liveweights for groups of cattle. To achieve

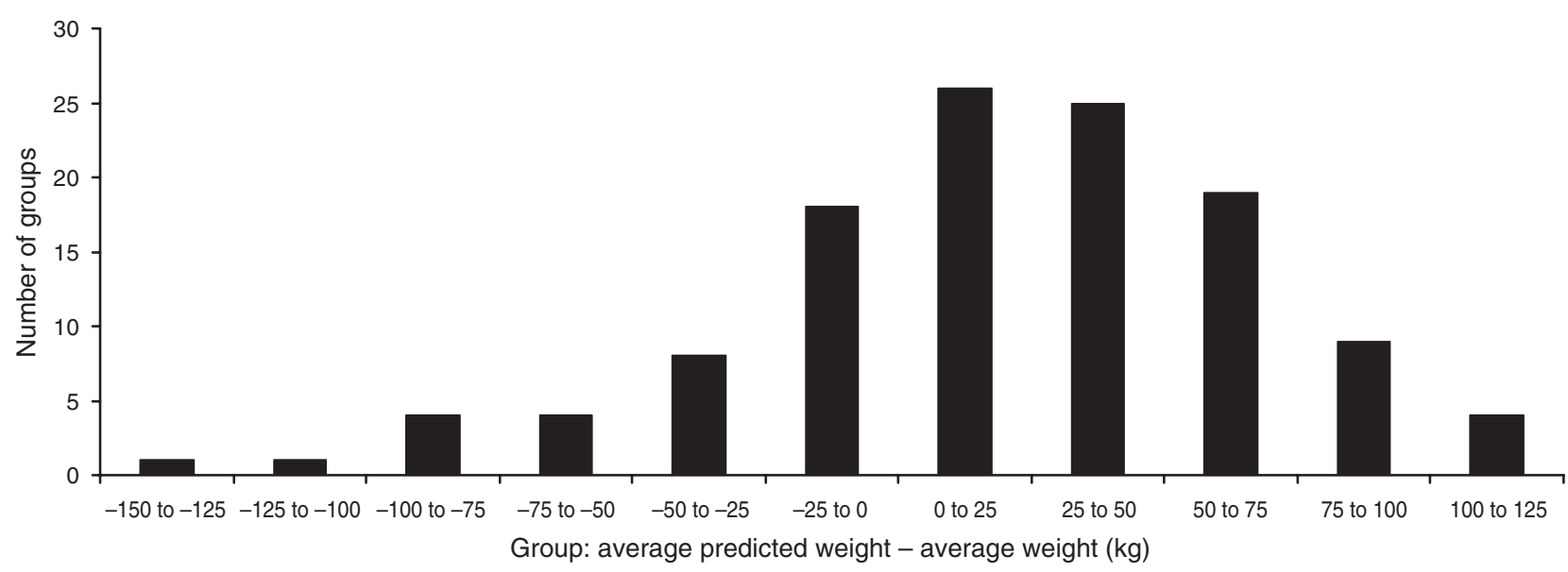

Fig. 4. Distribution of the group difference between average predicted and average recorded liveweights in 83 validation population groups weighed a combined total of 119 times (20917 observations).

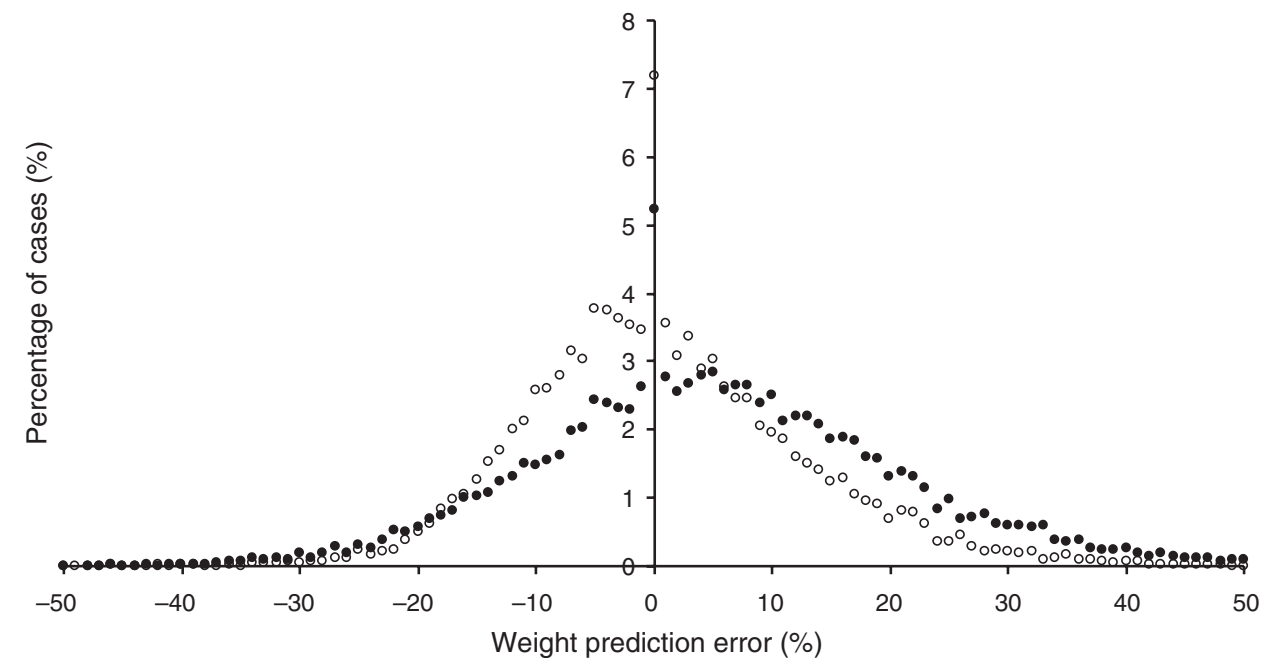

Fig. 5. Distribution (\%) of error in predicting liveweights using the condition score equations in the test group $(n=17372$; open dots $)$ and the validation population $(n=20917$; closed dots $)$. 
95\% (within two standard errors of the mean) of group average liveweight predictions (condition score used in equations) within $5,4,3,2$ and $1 \%$ of actual average liveweight requires 23,36 , 62, 137 and 521 females, respectively, given precision of measurements matches that used in the research.

As use of either condition score or subcutaneous rump fat thickness (P8 site) in the analyses produced very similar effects, precision and accuracy, condition score is appropriate to use in the liveweight prediction method despite it being a subjective assessment and prone to variation. Using condition score for liveweight prediction is preferred to P8 fat depth or EMA as ultrasound equipment to measure these is not readily available.

Our methods did not produce a curvilinear stage of pregnancy effect which fully overlaid previously published values for weights of the gravid uterus. Within the error variation that occurred there was no significant difference between all curves shown. Further, the predicted effect of fetal age on liveweight was not less than the expected average weight of pregnancy. It is concluded that pregnancy adds weight to cows at all stages, rather than displacing weight. This validates correction of liveweight for stage of pregnancy by subtracting estimated weight of the gravid uterus (Silvey and Haydock 1978; O'Rourke et al. 1991).

Liveweight varied by $12-14 \%$ per score as cows differed from moderate body condition. Therefore, for example, a 460-kg cow in moderate condition (score 3 ) will change liveweight by $\sim 60 \mathrm{~kg}$ per change in condition score. The linear effect of condition score on weight demonstrated that the 5-point condition scoring system used was accurately representing what the scoring system assesses. Five-point scoring with half- or third-score increments as required is a practical method for any subjective assessment. Anecdotal evidence is that this approach is being increasingly adopted to replace the wide range of 5- to 9-point systems (Gaden 2005) that have been used around the world.

There was a range in liveweight difference of $10-40 \%$ between non-pregnant Brahmans and Bos taurus female cattle at the same height and body condition score. The difference was less in taller, thus older, cattle in poorer body condition. Though these two subspecies interbreed readily, this highlights a substantial conformational difference.

The site effects on liveweight were a direct effect of curfews and much higher than expected. Fordyce et al. (2008) reported that in northern Australia, a full feed and water curfew causes an average $0.3 \%$ liveweight loss per $\mathrm{h}(7.5 \%$ day $)$, and that restriction only from feed causes a liveweight loss of $0.06-0.25 \%$ per h $(1.5-6 \% /$ day $)$. At the Swan's Lagoon site, cattle were usually weighed within $16 \mathrm{~h}$ of yarding and separation from water in the afternoon. However, many of these cattle would have last had a drink early that day, which would explain most of the $7-10 \%$ decreases in liveweight. Although cattle had access to water at both Brian Pastures and Toorak, they may not have drunk for up to $24 \mathrm{~h}$ before weighing if their normal behaviour was to drink once daily, which may account for the 2-4\% lower liveweights at Brian Pastures and 2-9\% lower liveweights at Toorak than at Belmont for the same animal class. We are unable to explain the $2-8 \%$ higher liveweights at Brigalow, except for the possible effects of unbalanced data due to only data for mature cows being recorded at this site and/or cows at Brigalow usually drinking closer to weighing time than cows at Belmont. Checks suggested that the methods, including scales accuracy, were as described. The similarity of site effects in models fitted with either body condition score, P8 fat depth or EMA indicates that the error is unlikely to be in any of these measures.

In the transition from the late dry season to the wet season, cattle have high short-term liveweight loss and recovery (McLean et al. 1983). We were unable to discern this effect or any other consistent effect of estimated dietary DMD on liveweight in our study as no measurements were conducted in the transition period, which usually coincided with calving when animal handling was avoided.

The average liveweight overestimate of $19 \mathrm{~kg}(6 \%)$ and the higher error of prediction in the validation population than in the test group highlight the challenges of standardising weighing protocols and other animal assessments under extensive commercial grazing conditions. Test group measures were conducted by a highly disciplined science group; validation population measures were conducted by a large number of cattle veterinarians and technicians under a large range of conditions across northern Australia after limited calibration of techniques. This outcome is an example of one use of the methods developed in this report, i.e. to assess the accuracy and precision of liveweights that have been recorded.

A simple effect may have been variation in condition scoring standards. The authors have previously noted up to a full score difference given for the same animals between two scorers. This could account for up to $10 \%$ prediction error in specific situations. Regular testing of scales accuracy during weighing may not have occurred under commercial conditions. There is an estimated $2.5 \%$ increase in liveweight with each $10 \%$ decrease in percentage Bos indicus at the same hip height. Errors in visually estimating proportion of Bos indicus for each weighing group in the validation population could easily have been as high as $25 \%$, which could result in liveweight prediction errors of up to $6 \%$ in crossbred cattle.

Handling before weighing effects under commercial conditions were also likely to have lowered precision and accuracy of weighing. Weighing was conducted within a 2-3-h period in each test group assessment. However, in the validation population, measurements extended up to a full day, thus introducing an average curfew effect of a quarter of a day, which is equivalent to a $\sim 2 \%$ overestimate (Fordyce et al. 2008). The time between first disturbing an animal in a paddock and weighing in a commercial situation is usually much longer than occurred in the test groups as paddock size is much larger on average. Also, water and feed is typically less available during musters and yarding than at the test sites. Together with being mustered longer distances in larger groups, these factors increase the potential for more dehydration, thus further reducing recorded liveweights in comparison to predicted liveweights, even when curfew effects as indicated in the methods were applied. This is substantiated by the outcome that average prediction error was 7, 29 and $42 \mathrm{~kg}$ (2,8 and 13\%, respectively), for cows assessed in central and southern Queensland, northern Queensland, and the Northern Territory and Western Australia, respectively. The effects discussed are amplified in moving from southern Queensland to north-west Western Australia.

The liveweight prediction method was developed using over 2000 representative beef cattle that were assessed over 17000 times at all ages between weaning and maturity in a range of 
environments. However, it is not applicable in cattle under 6 months of age or $100 \mathrm{~cm}$ in height as no suckling calf data was used; this is reinforced by regression coefficients of liveweight on height predicting negative liveweights for height lower than in the data range used.

The major conclusion from this study is that average liveweight of groups of post-weaning age female beef cattle in the tropics can be estimated from simple measurements, with the error of estimation being less than $1 \%$ if sufficient cattle are assessed with adequate precision and accuracy. This is a valuable tool in assessing the accuracy of liveweights and other data recorded at the same time. The study also demonstrated that pregnancy adds to cow liveweight without displacement. Measures of fatness such as body condition score were found to be linearly related to liveweight. A final conclusion was that diet quality is not useful in predicting liveweight, though this will not apply immediately after a major diet change.

\section{Acknowledgements}

Operational funding was provided by the Cooperative Centre for Beef Genetic Technologies (Beef CRC: Project 4.1.3b) and Meat and Livestock Australia (Project B.NBP.0382). We sincerely thank the inputs of the large group of people involved in research design and management, managing the cattle and collecting the data. Special thanks are due to Dr Heather Burrow (BeefCRC), Tracy Longhurst, Russ Tyler, Peggy Olsson, Debra Corbet, Neil Cooper, Dave Smith, Dr Brian Burns (DAFF: Department of Agriculture, Fisheries \& Forestry, Queensland), Warren Sim (CSIRO), David Johnston, Steve Barwick (Animal Genetics and Breeding Unit, Armidale), Professor Michael McGowan (University of Queensland), Tom Newsome, Don Menzies (Outcross) and Dr Sandi Jephcott (Chinchilla Veterinary Clinic). Many other DAFF and CSIRO staff also assisted.

\section{References}

Barwick SA, Johnston DJ, Burrow HM, Holroyd RG, Fordyce G, Wolcott ML, Sim WD, Sullivan MT (2009) Genetics of heifers performance in 'wet' and 'dry' seasons and their relationships with steer performance in two tropical beef genotypes. Animal Production Science 49, 367-382. doi:10.1071/EA08273
Burns BM, Reid DJ, Taylor JF (1997) An evaluation of growth and adaptive traits of different cattle genotypes in a subtropical environment. Australian Journal of Experimental Agriculture 37, 399-405. doi:10.1071/EA96092

Coates DB, Dixon RM (2008) Faecal near infrared reflectance spectroscopy estimates of diet quality and responses to nitrogen supplements by cattle grazing Bothriochloa pertusa pastures. Australian Journal of Experimental Agriculture 48, 829-834. doi:10.1071/EA08004

Fordyce G, Williams PJ, Sim WD, Young RJ, Hall RL (2008) Correcting cattle liveweights in the tropics for weighing protocol. Animal Production in Australian 27, 56.

Gaden B (2005) Final Report, Project LIVE.120, Meat and Livestock Australia, North Sydney.

Johnson ER, Vidyadaran MK (1981) An evaluation of different sites for measuring fat thickness in the beef carcass to determine carcass fatness. Australian Journal of Agricultural Research 32, 999-1007. doi:10.1071/ AR9810999

McGowan MR (2012) Crunching the cash cow numbers. Feedback, Meat and Livestock Australia, Sydney.

McLean RW, McCown RL, Little DA, Winter WH, Dance RA (1983) An analysis of cattle live-weight changes on tropical grass pasture during the dry and early wet seasons in northern Australia. Journal of agricultural Science, Cambridge 101, 17-24.

O'Rourke PK, Entwistle KW, Arman C, Esdale CR, Burns BM (1991) Fetal development and gestational changes in Bos taurus and Bos indicus genotypes in the tropics. Theriogenology 36, 839-853. doi:10.1016/ 0093-691X(91)90350-M

Payne RW, Harding SA, Murray DA, Soutar DM, Baird DB (2008) 'GenstAT. Release 13.' (VSN International Pty Ltd: Hemel Hempstead, Hertfordshire, UK)

Robbins GB, Laing AR, Bushell JJ, Ash AJ (1982) Effect of selling system for store steers on liveweight and subsequent performance in a feedlot. Proceedings of the Australian Society of Animal Production 14, 381-384.

Silvey MW, Haydock KP (1978) A note on live-weight adjustments for pregnancy in cows. Animal Production 27, 113-116. doi:10.1017/ $\mathrm{S} 0003356100035881$ 